\title{
PENGARUH BUDAYA ORGANISASI TERHADAP KINERJA KARYAWAN MELALUI VARIABEL INTERVENING KOMITMEN ORGANISASI PADA CV. AUTO 99 MALANG
}

\author{
Tatik Budiarti \\ M.Bukhori \\ Dosen STIE AsiA Malang
}

\begin{abstract}
This study aims to determine the effect of variable of organizational culture on employee performance, variable organizational commitment to employee performance and organizational culture variables on the performance of employees through the organization's commitment to CV AUTO 99 Malang. This type of research is Eksplanatory Research, the research method is quantitative. The population in this study amounted to 57 employees. The total sample of 57 employees using the technique of saturated samples (Path). Anailsis deskiptif This study uses quantitative and statistical analysis used to determine the direct and indirect relationships between the variables of organizational culture, organizational commitment variable and variable employee performance.
\end{abstract}

The results obtained organizational culture variables directly affect organizational commitment and also directly affects the performance of employees. Organizational commitment directly affects the performance of employees and organizational culture are also indirect effect on employee performance through organizational commitment to the CV. AUTO 99 Malang.

Keywords: Organizational Culture, Organizational Commitment and Employee Performance.

\begin{abstract}
ABSTRAK
Penelitian ini bertujuan untuk mengetahui pengaruh variabel budaya organisasi terhadap kinerja karyawan, variabel komitmen organisasi terhadap kinerja karyawan dan variabel budaya organisasi terhadap kinerja karyawan melalui komitmen organisasi di CV AUTO 99 Malang. Jenis penelitian adalah Eksplanatory Research, metode penelitian adalah kuantitatif. Populasi dalam penelitian ini berjumlah 57 karyawan. Jumlah sampel sebanyak 57 karyawan dengan menggunakan teknik sampel jenuh (Path). Penelitian ini menggunakan anailsis deskiptif kuantitatif dan analisis statistik yang digunakan untuk mengetahui hubungan langsung dan tidak langsung antara variabel budaya organisasi, variabel komitmen organisasi dan variabel kinerja karyawan.

Hasil yang didapatkan variabel budaya organisasi berpengaruh secara langsung terhadap komitmen organisasi dan juga berpengaruh secara langsung terhadap kinerja karyawan. Komitmen organisasi berpengaruh langsung terhadap kinerja karyawan dan juga budaya organisasi berpengaruh secara tidak langsung terhadap kinerja karyawan melalui komitmen organisasi pada CV. AUTO 99 Malang.
\end{abstract}

Kata kunci: Budaya Organisasi, Komitmen Organisasi dan Kinerja Karyawan.

\section{PENDAHULUAN}

Dalam dunia manajemen, fungsi organisasi terutama dalam hal pengawasan, organisasi perlu memantau kegiatan para pekerjanya terhadap sikap, dan hubungannya dengan perilaku dalam kegiatan berorganisasi atau kegiatan kerjanya sehari-hari. Dan saat ini budaya organisasi dan komitmen organisasi merupakan instrument yang memfokuskan pada pekerja, agar terhindar dari sikap dan juga perilaku SDM yang kurang baik dan agar dapat meningkatkan produktivitas kerja untuk menghadapi berbagai tantangan di masa yang akan datang. Ini pula yang akan diterapkan dalam perusahan CV. AUTO 99 Malang, yang beralamat di Jl.Soekarno-Hatta No 31 Malang merupakan perusahaan yang bergerak dalam bidang Body Shop, Paint and Repair mobil. Seperti yang dijelaskan oleh Mathis dan Jackson (2004) menyatakan bahwa kinerja pada dasarnya adalah apa yang dilakukan atau tidak dilakukan pegawai. Karyawan dapat bekerja dengan baik bila memiliki kinerja yang tinggi sehingga dapat menghasilkan kerja yang baik. Kinerja karyawan bisa dilihat melalui indikator seperti kualitas, kuantitas, pelaksanaan tugas dan juga tanggung jawab terhadap pekerjaannya. Selanjutnya kinerja yang baik juga bisa dipengaruhi oleh komitmen dan budaya di organisasi tersebut.

Seperti yang dijelaskan oleh Robbins dan Judge, (2008) mendefinisikan bahwa "Komitmen organisasi adalah suatu keadaan di mana seorang karyawan memihak organisasi 
tertentu serta tujuan-tujuan dan keinginannya untuk mempertahankan keanggotaan dalam organisasi tersebut. Selain itu mengapa budaya organisasi itu perlu dalam suatu organisasi tentunya sebagai pembeda antara organisasi satu dengan lainnya. Seperti yang dijelaskan Robbins (2008), budaya organisasi adalah suatu persepsi bersama yang dianut oleh anggotaanggota organisasi itu.

Berdasarkan latar belakang masalah diatas, maka penulis tertarik untuk melakukan penelitian disuatu perusahaan mengenai "Pengaruh Budaya Organisasi Terhadap Komitmen Organisasi dan Kinerja Karyawan Pada CV. AUTO 99 Malang”.

\section{Rumusan Masalah}

Latar belakang diatas maka rumusan masalah yang akan dibahas dalam penelitian ini adalah:

1. Apakah budaya organisasi berpengaruh secara langsung terhadap komitmen organisasi pada CV. AUTO 99 Malang ?

2. Apakah budaya organisasi berpengaruh langsung terhadap kinerja karyawan pada CV. AUTO 99 Malang ?

3. Apakah terdapat pengaruh langsung antara komitmen organisasi terhadap kinerja karyawan pada CV. AUTO 99 Malang ?

4. Apakah budaya organisasi berpengaruh secara tidak langsung terhadap kinerja karyawan melalui komitmen organisasi pada CV. AUTO 99 Malang ?

\section{LANDASAN TEORI}

\section{Kinerja Karyawan}

Pada dasarnya kinerja merupakan hasil kerja secara kualitas dan kuantitas yang dicapai oleh seorang pegawai dalam melaksanakan tugasnya sesuai dengan tanggungjawab yang diberikan kepadanya (A.A. Anwar Prabu Mangkunegara (2009). Mathis (2004) menyatakan bahwa kinerja pada dasarnya adalah apa yang dilakukan atau tidak dilakukan oleh pegawai. Indikator dari kinerja karyawan menurut Anwar Prabu (2009) yaitu:

1) Kualitas

2) Kuantitas

3) Pelaksanaan Tugas

4) Tanggung Jawab

\section{Komitmen Organisasi}

Robbins dan Judge (2008) mendefinisikan komitmen sebagai suatu keadaan dimana seorang individu memihak organisasi serta tujuan-tujuan dan keinginannya untuk mempertahankan keangotaannya dalam organisasi. Sedangkan Mathis dan Jackson (dalam Sopiah) mendefinisikan komitmen organisasional sebagai derajad dimana karyawan percaya dan mau menerima tujuantujuan organisasi dan akan tetap tinggal atau tidak akan meninggalkan organisasinya. Indikator dalam komitmen organisasi menurur Robbins and Judge (2008) yaitu: 1) Komitmen Afektif (affective

2) Komitmen Berkelanjutan (continue commitment)

3) Komitmen Normatif (normative commitment)

\section{Budaya Organisasi}

Sistem makna bersama ini bila diamati dengan lebih seksama, merupakan seperangkat karakteristik utama yang dihargai oleh organisasi itu (Robbins dan Judge, 2008). Budaya organisasi adalah suatu sistem nilai yang diperoleh dan dikembangkan oleh organisasi dan pola kebiasaan dan falsafah dasar pendirinya, yang terbentuk menjadi aturan yang digunakan sebagai pedoman dalam berfikir dan bertindak dalam mencapai tujuan organisasi. Indikator dalam suatu budaya organisasi menurut Fey and Denison (2003) diantaranya sebagai berikut:

1) Involvement (keterlibatan)

2) Consistensy (konsistensi

3) Adaptability (adaptabilitas)

4) Mission (misi)

\section{Kerangka Berpikir dan Konseptual}

Berdasarkan pada teori-teori yang dibahas diatas, maka dapat dirumuskan kerangka konseptual dari penelitian seperti pada gambar dibawah ini :

\section{Gambar 1}

Kerangka Konseptual

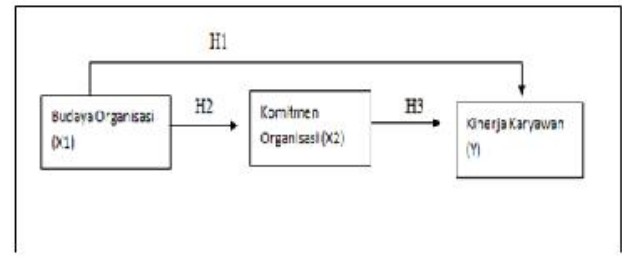

Hipotesis

Dari model kerangka konseptual diatas, maka hipotesis penelitiannya adalah sebagai berikut:

H1: Diduga ada pengaruh langsung antara variabel budaya organisasi terhadap komitmen organisasi.

H2: Diduga ada pengaruh langsung antara variabel budaya organisasi terhadap kinerja karyawan.

H3: Diduga ada pengaruh langsung antara variabel komitmen organisasi terhadap kinerja karyawan. 
H4: Diduga ada pengaruh tidak langsung antara budaya organisasi terhadap kinerja karyawan melalui komitmen organisasi.

\section{METODE PENELITIAN}

\section{Jenis Penelitian}

Penelitian ini menggunakan jenis penelitian Eksplanatory Research. Menurut Singarimbun (2006). "Ekspalanatory Research adalah penelitian yang menjelaskan hubungan kausal antara variabel-variabel penelitian melalui uji hipotesis yang telah dirumuskan sebelumnya". Unit analisi dalam penelitin ini adalah karyawan pada CV. AUTO 99 Malang. Populasi dalam penelitian ini adalah seluruh karyawan CV. AUTO 99 Malang sebanyak 57 orang. Penelitian ini dilaksanakan dengan menggunakan penarikan sampel yaitu sampling jenuh, dimana semua anggota populasi dijadikan sebagai sampel. Menurut Sugiyono (2008), sampling jenuh atau sensus adalah teknik penentuan sampel bila semua anggota populasi digunakan sebagai sampel".

\section{Metode Pengumpulan Data}

$$
\begin{array}{ll}
\text { 1. } & \text { Observasi } \\
\text { 2. Kuesioner } \\
\text { 3. Dokumentasi } \\
\text { 4. Wawancara }
\end{array}
$$

Definisi Operasional Variabel

Variabel Bebas (Independent Variabel (X)). Variabel Independen (Variabel Bebas) adalah variabel yang mempengaruhi atau sebab perubahan timbulnya variabel terikat (dependen). Dalam penelitian ini yang merupakan variabel bebas adalah Budaya Organisasi $\left(\mathrm{X}_{1}\right)$

\section{Budaya Organisasi}

Budaya organisasi adalah suatu sistem nilai yang diperoleh dan dikembangkan oleh organisasi yang kemudian dianut oleh seluruh anggota CV. AUTO 99 Malang dan yang membedakan organisasi satu dengan yang lainnya.

Variabel Intervening (X2)

\section{Variabel}

adalah variabel intervening adalah

lainnya

variabel-variabel yang mempengaruhi hubungan aantara variabel-variabel independen dengan variabel-variabel dependen menjadi hubungan yang tidak langsung. Variabel intervening dalam penelitian ini adalah Komitmen Organisasi.

\section{Komitmen Organisasi (X2)}

Mathis dan Jackson (dalam Sopiah) mendefinisikan komitmen organisasional sebagai derajad dimana karyawan percaya dan mau menerima tujuan-tujuan organisasi dan akan tetap tinggal atau tidak akan meninggalkan organisasinya. Seperti yang diterapkan karyawan CV. AUTO 99 Malang.

Variabel Terikat (Dependent Variabel (Y))

Variabel terikat merupakan variabel yang dipengaruhi atau yang menjadi akibat, karena adanya variabel bebas (Sugiyono, 2008). Variabel terikat dalam penelitian ini adalah Kinerja Karyawan.

Kinerja Karyawan (Y)

Kinerja karyawan merupakan hasil kerja secara kualitas maupun kuantitas yang dicapai oleh seseorang dalam melaksanakan tugas yang diberikan kepadanya sesuai dengan standart atau kriteria yang telah ditetapkan oleh CV. AUTO 99 Malang.

\section{Metode Analisis Data}

Uji Validitas

Uji validitas dilakukan untuk mengetahui tingkat kevalidan indikator yang digunakan sebagai alat ukur variabel. Pengujian validitas menggunakan korelasi bivariate yang dilakukan dengan menghitung korelasi antara skor masing-masing butir pertanyaan dengan total skor variabel, dengan ketentuan sig. $\$ 0,05$ berarti valid dan sig. $>0,05$ berarti tidak valid (Arikunto, 2006). Hasil perhitungan menunjukkan bahwa semua korelasi antara skor masing-masing pertanyaan dengan total skor variabel significansinya bernilai kurang dari 0,05 sehhingga dikatakan valid.

\section{Uji Reliabilitas}

Menurut Singarimbun (2006) meyatakan bahwa reliabilitas adalah indeks yang menunjukkan sejauh mana suatu alat pengukur dapat dipercaya atau dapat diandalkan. Dengan ketentuan jika nilai Cronbach Alpha $\geq 0.60$, maka item pernyataan dinyatakan reliabel.

Tabel 1

Hasil Uji Reliabilitas Instrument Budaya Organisasi (X1)

\section{Reliability Statistics}

\begin{tabular}{|r|r|}
\hline $\begin{array}{c}\text { Cronbach's } \\
\text { Alpha }\end{array}$ & N of ltems \\
\hline .965 & 8 \\
\hline
\end{tabular}

Berdasarkan tabel 2 Cronbach Alpha $\geq$ 0,60 yaitu 0,965. Maka hasil uji reliabiltas instrumen budaya organisasi (X1) dinyatakan reliabel karena nilai Cronbach Alpha $\geq 0,60$

Tabel 2

Hasil Uji Reliabilitas Instrument komitmen organisasi (X2) 
Reliability Statistics

\begin{tabular}{|r|r|}
\hline $\begin{array}{c}\text { Cronbach's } \\
\text { Alpha }\end{array}$ & N of ltems \\
\hline .875 & 6 \\
\hline
\end{tabular}

Berdasarkan tabel 3 Cronbach Alpha $\geq$ 0,60 yaitu 0,875. Maka hasil uji reliabiltas instrumen komitmen organisasi $\left(\mathrm{X}_{2}\right)$ dinyatakan reliabel karena nilai Cronbach Alpha $\geq 0,60$.

Tabel 3

Hasil Uji Reliabilitas Instrument Kinerja (Y)

Reliability Statistics

\begin{tabular}{|r|r|}
\hline $\begin{array}{c}\text { Cronbach's } \\
\text { Alpha }\end{array}$ & N of ltems \\
\hline .899 & 8 \\
\hline
\end{tabular}

Berdasarkan tabel 4 Cronbach Alpha $\geq$ 0,60 yaitu 0,899. Maka hasil uji reliabiltas instrumen Kinerja (Y) dinyatakan reliabel karena nilai Cronbach Alpha $\geq 0,60$.

Analisis Jalur (Path Analysis)

Analisis jalur digunakan untuk melukiskan dan menguji model hubungan antar variabel yang berbentuk sebab akibat (Sugiyono: 2009). Analisis jalur dilakukan sesuai dengan model substruktural yang telah ditentukan. Dimana substruktural 1 adalah X2= $\mathrm{Px}_{2} \mathrm{X}_{1}+\mathrm{e}_{1}$ dan substruktural 2 adalah $\mathrm{Y}=\mathrm{PyX}_{1}$ $+\mathrm{PyX}_{2}+\mathrm{e}_{2}$ serta substruktural 3 adalah $\mathrm{Y}=\{($ $\left.\left.\mathrm{Px}_{2} \mathrm{X}_{1}\right) \times\left(\mathrm{PyX}_{2}\right)\right\}+\mathrm{PyX}_{1}$. Diagram jalur dapat dilihat di gambar berikut:

Gambar 2

\section{Diagram jalur substruktural}

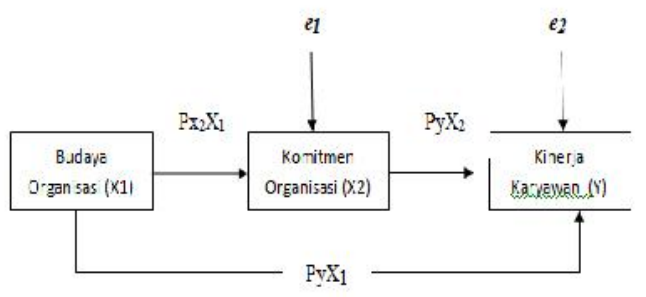

Sumber : datc dioleh tainun 2016

Uji Hipotesis

Pengujian Substruktural 1

Pengujian ini bertujuan untuk mengetahui seberapa besar pengaruh variabel budaya organisasi terhadap kinerja karyawan. Berikut ini adalah hasil sub-struktur 1.

Rumus : $\mathrm{X} 2=\mathrm{px}_{2} \mathrm{X}_{1}+\mathrm{e}_{1}$

Tabel 4

Model summary sub structural 1

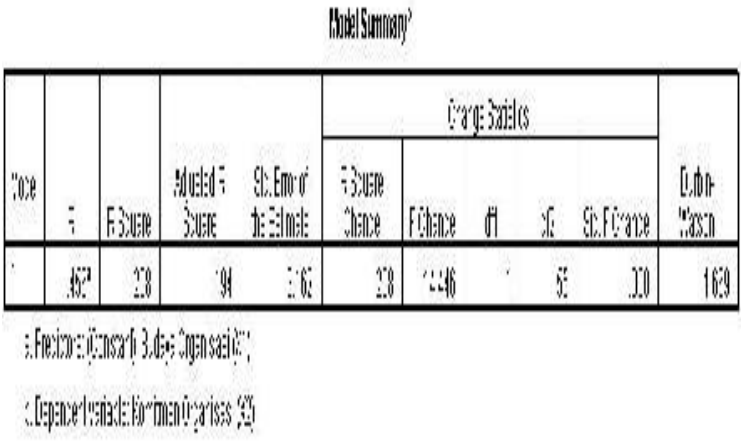

Sumber : data primer diolah tahun 2017.

Tabel 6

Coefficients Substruktural 1

Coefficients $^{2}$

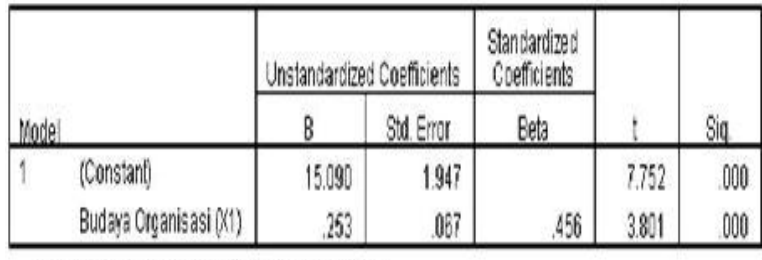

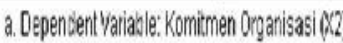

Sumber : data diolah tahun 2017.

Konstanta sebesar 15.090 menyatakan bahwa jika tidak ada kenaikan nilai dari variabel budaya organisasi (X1) maka nilai komitmen organisasi (X2) adalah 15.090. Koefisien jalur sebesar 0,456 artinya setiap nilai budaya organisasi meningkat $1 \%$ maka komitmen organisasi karyawan akan meningkat sebesar 0,456 .

1) Pengaruh Budaya organisasi terhadap Komitmen organisasi.

H1: Ada pengaruh langsung yang signifikan antara budaya organisasi terhadap komitmen organisasi

Hipotesis diatas ingin mengetahui pengaruh langsung antara budaya organisasi terhadap komitmen organisasi. Pada tabel 6 coefficients substruktural 1 diatas dapat diketahui nilai sig. dari budaya organisasi adalah 0,000. Karena nilai sig. variabel lebih kecil dari 0,05 $(0,000<0,05)$, maka H1 diterima, artinya ada pengaruh langsung yang signifikan antara budaya organisasi terhadap komitmen organisasi.

Gambar 3

Model Jalur Substruktural 1 


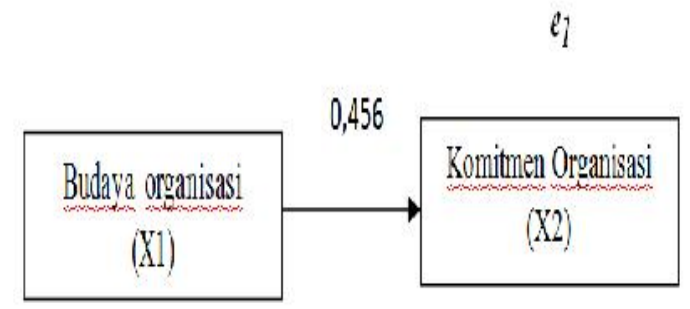

Sumber : Data diolah tahun 2017.

\section{Pengujian Substruktural 2}

Pengujian sub-struktur 2 dianalisis dari output SPSS pertama dimana variabel budaya organisasi dan komitmen organisasi sebagai variabel bebas dan kinerja karyawan sebagai variabel terikat. Pengujian ini bertujuan untuk mengetahui seberapa besar pengaruh variabel budaya organisasi, dan komitmen organisasi terhadap kinerja karyawan. Berikut ini adalah hasil sub-struktur 2. Rumus : $\mathrm{Y}=\mathrm{pYx}_{1} \mathrm{X}_{1}+$ $\mathrm{pYX} 2 \mathrm{X} 2+\mathrm{e}_{2}$

\section{Tabel 6}

Model Summary Substrutural 2

Madisintrot?

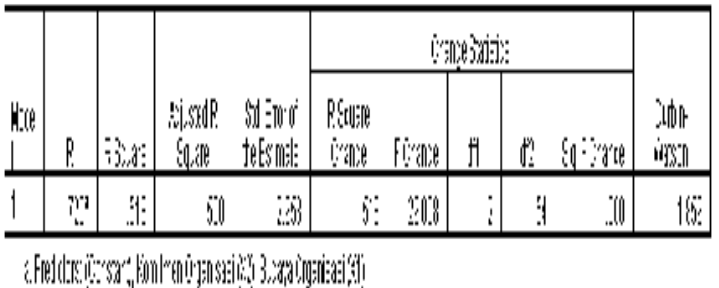

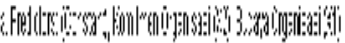

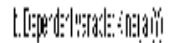

Sumber : Data primer diolah tahun 2017.

Tabel 7

\section{Coeficient Substrutural 2}

Coeficientits

\begin{tabular}{|c|c|c|c|c|c|}
\hline \multirow[b]{2}{*}{ Diloc:21 } & \multicolumn{2}{|c|}{ Jritar Jar zedcoe } & \multirow{2}{*}{$\begin{array}{c}\text { Eancatc zec } \\
\text { icafficients } \\
\text { Eata }\end{array}$} & \multirow[b]{2}{*}{ l } & \multirow[b]{2}{*}{ E]. } \\
\hline & $E$ & 进: Entor & & & \\
\hline 'Coritar:", & 11.645 & 2635 & & 422 & .00 \\
\hline 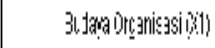 & : & .60 & .230 & 2168 & .035 \\
\hline 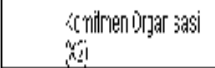 & 66 & .126 & $.50 \%$ & $50 \%$ & .000 \\
\hline
\end{tabular}

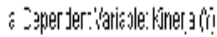

Sumber : Data primer diolah tahun 2017.

Berdasarkan tabel 8 Coefficients substruktural 2 menggambarkan bahwa persamaan sebagai berikut: $\mathrm{Y}=\mathrm{pyX}_{1}+$ pyX2+ $\mathrm{e}_{2}$

Konstanta sebesar 11,649 menyatakan bahwa jika tidak ada kenaikan nilai dari variabel budaya organisasi (X1) dan Komitmen organisasi (X2), maka nilai kinerja karyawan sebesar 11,649. Koefisien regresi budaya organisasi sebesar 0,230 yang artinya jika ada peningkatan nilai budaya organisasi sebesar $1 \%$, maka terjadi peningkatan kinerja sebesar 0,230 dan juga koefisien regresi komitmen organisasi sebesar 0,585 yang artinya jika ada peningkatan nilai variabel komitmen organisasi sebesar $1 \%$ maka kinerja karyawan meningkat sebesar 0,585 .

\section{1) Pengaruh Langsung Budaya} organisasi terhadap Kinerja Karyawan

$\mathrm{H} 2$ : Ada pengaruh langsung yang signifikan antara budaya organisasi terhadap kinerja karyawan.

Hipotesis diatas ingin mengetahui pengaruh langsung antara budaya organisasi terhadap kinerja karyawan. Pada tabel 8 coefficients substruktural 2 diatas dapat diketahui nilai sig. dari variabel budaya organisasi adalah 0,035. Karena nilai sig. variabel lebih kecil atau sama dengan 0,05 $(0,035 \leq 0,05)$, maka H2 diterima, artinya ada pengaruh langsung yang signifikan antara budaya organisasi terhadap kinerja karyawan.

\section{2) Pengaruh Langsung Komitmen} organisasi terhadap Kinerja Karyawan.

H3: Ada pengaruh langsung yang signifikan antara komitmen organisasi terhadap kinerja karyawan.

Hipotesis di atas ingin mengetahui pengaruh langsung antara komitmen organisasi terhadap kinerja karyawan. Pada table 8 coefficients substruktural 2 diatas dapat diketahui nilai sig. dari variabel komitmen organisasi adalah 0,000. Karena nilai sig. variabel lebih kecil atau sama dengan 0,05 $(0,000 \leq 0,05)$, maka H3 diterima, artinya ada pengaruh langsung yang signifikan antara komitmen organisasi terhadap kinerja karyawan. $\mathrm{Y}=0,230 \mathrm{X} 1+0,585 \mathrm{X} 2+\mathrm{e}_{2}$

\section{Gambar 4}

Model Jalur Substruktural 2

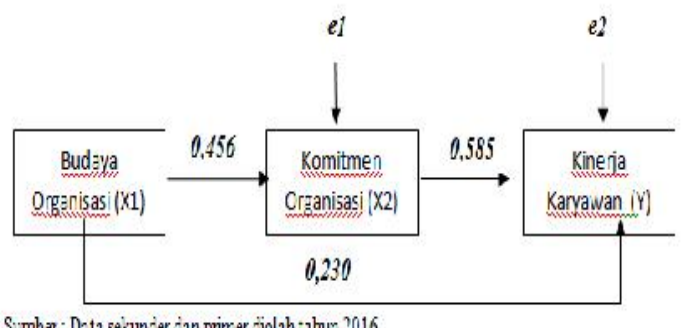

Dari kedua substruktural diatas, dapat diperoleh hasil dari hipotesis pengaruh secara tidak langsung dari variabel budaya organisasi (X1) terhadap kinerja karyawan (Y) melalui komitmen organisasi (X2).

3) Pengaruh Budaya organisasi terhadap 
Kinerja Karyawan melalui Komitmen organisasi.

H4 : Diduga ada pengaruh tidak langsung antara Budaya Organisasi terhadap kinerja karyawan melalui komitmen organisasi.

Hipotesis diatas ingin mengetahui pengaruh tidak langsung antara budaya organisasi terhadap kinerja karyawan melalui komitmen organisasi. Pada tabel 8 coefficients substruktural 2 diatas dapat diketahui nilai sig. dari budaya organisasi adalah 0,035 karena nilai sig. lebih kecil dari $0,05(0,035<0,05)$ maka H4 diterima. Demikian variabel komitmen organisasi adalah nilai sig 0,000 dan lebih kecil dari $0,05(0,000<0,05)$. Dengan begitu maka H4 diterima, artinya ada pengaruh tidak langsung yang signifikan antara budaya organisasi terhadap kinerja karyawan melalui komitmen organisasi. Gambar jalur substruktural 3 dilihat pada gambar 5:

$\mathrm{Y}=\left\{\left(\mathrm{Px}_{2} \mathrm{X}_{1}\right)_{\mathrm{X}}\left(\mathrm{PyX}_{2}\right)\right\}+\mathrm{PyX}_{1}$

$\mathrm{Y}=0,456 \mathrm{X} 1 \times 0,585 \mathrm{X} 2+0.230$

Gambar 5

Model Jalur Substruktural 3

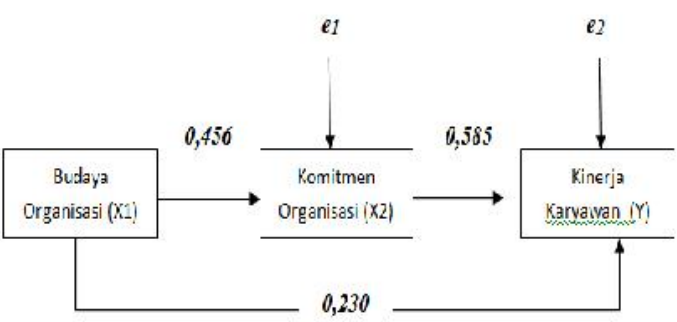

Sumber : Data sekunder dan primer diolah tahun 2016

Analisis Jalur (Path Analysis)

Gambar 6

Diagram Analisi Jalur (Path)

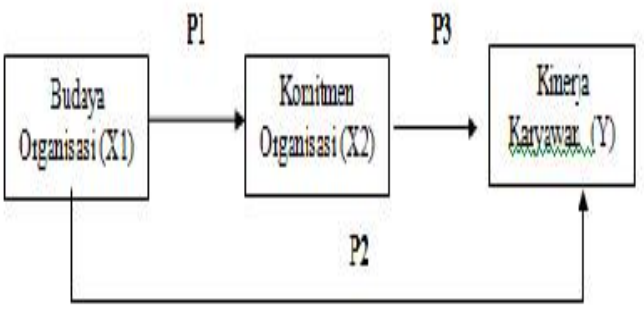

Untuk menghitung besarnya pengaruh tidak langsung dan pengaruh total dihitung dengan cara:

a. Pengaruh langsung budaya organisasi ke komitmen organisasi $=\mathrm{P} 1$

b. Pengaruh langsung budaya organisasi ke kinerja $=\mathrm{P} 2$

c. Pengaruh langsung komitmen organisasi ke kinerja $=\mathrm{P} 3$

d. Pengaruh tidak langsung gaya kepempinan ke kinerja melalui

Gambar 7

Komitmen organisasi $=\mathrm{P} 1 \times \mathrm{P} 3$

Diagram Penyajian Data Analisis Jalur (Path)

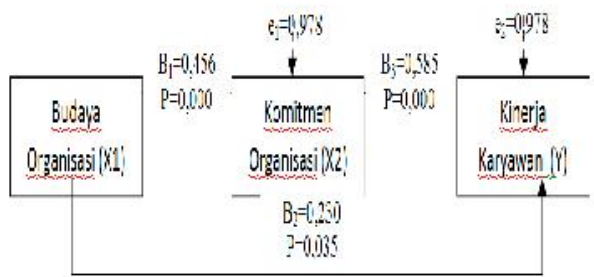

Sumber : Data diolah tahun 2017

Dari gambar 7 diatas dapat disusun dalam sebuah tabel penyajian analisis jalur (path) untuk mengetahui nilai koefisien jalur pengaruh secara langsung maupun tidak langsung dalam penelitian ini. Penyajian analisis jalur dalam bentuk tabel dapat dilihat pada tabel di bawah ini :

Tabel 8

Penyajian Data Analisis Jalur (Path)

\begin{tabular}{|c|c|c|c|}
\hline Variabel & Langung & Tidak Langung & Iotal \\
\hline X1 tertadis XI & 0,456 & . & 0,456 \\
\hline $\mathrm{X} 1$ remadap Y & 0,230 & . & 0,230 \\
\hline XI Enladia $Y$ & 0,585 & - & 0,585 \\
\hline$X_{1}$ endadap $Y$ melaluiX & - & $\begin{array}{c}(0,456 \times 0,585) \\
=0,267\end{array}$ & $\begin{array}{c}0.267+0,230 \\
=0.497\end{array}$ \\
\hline
\end{tabular}

Sumber : data diolah tahun 2017.

Pembahasan

Pada bagian ini akan dipaparkan pembahasan mengenai hasil analisis yang telah dilakukan. Dapat diketahui bahwa variabel independen berpengaruh signifikan terhadap variabel dependen baik secara langsung maupun tidak langsung melalui variabel intervening.

Untuk melakukan perhitungan secara langsung dan tidak langsung dilakukan dari nilai standardized coefficients regresi masing-masing variabel independen terhadap variabel dependent.

Pengaruh Budaya organisasi terhadap Komitmen organisasi

Hasil penelitian ini membuktikan bahwa budaya organisasi mempunyai pengaruh positif dan signifikan terhadap komitmen organisasi pada karyawan CV. AUTO 99 Malang, artinya budaya organisasi yang ada 
dalam perusahaan akan menjadi dasar karyawan untuk bekerja karena budaya organisasi yang dipegang oleh karyawan akan mempengaruhi perilaku individu dalam bekerja.

Dari hasil penelitian, pengujian statistik menunjukkan bahwa pengaruh langsung budaya organisasi terhadap komitmen organisasi memiliki koefisien jalur sebesar 0,456 dan secara statistik signifikan pada level $\alpha=0,05$ yang ditunjukkan dengan nilai signifikan tabel sebesar 0,000 (lebih kecil dari 0,05). Dari temuan statistik tersebut dapat dinyatakan bahwa budaya organisasi berpengaruh langsung dan signifikan terhadap komitmen organisasi (X2) sebesar 0,456 atau 45,6\%. Koefisien jalur sebesar 0,456 menunjukkan bahwa jika budaya organisasi meningkat $1 \%$ maka komitmen organisasi karyawan akan meningkat 0,456.

Pengaruh Langsung Budaya organisasi Terhadap Kinerja Karyawan

Hasil penelitian ini membuktikan bahwa budaya organisasi mempunyai pengaruh langsung terhadap kinerja pada karyawan CV. AUTO 99 Malang. Dari hasil penelitian, pengujian statistik menunjukkan bahwa pengaruh langsung budaya organisasi terhadap kinerja karyawan memiliki koefisien jalur sebesar 0,230 dan secara statistik signifikan pada level $\alpha=0,05$ yang ditunjukkan dengan nilai signifikan tabel sebesar 0,035 (lebih kecil dari 0,05). Dari temuan statistik tersebut dapat dinyatakan bahwa budaya organisasi berpengaruh langsung dan signifikan terhadap kinerja (Y) sebesar 0,230 atau 23\%. Koefisien jalur sebesar 0,230 menunjukkan bahwa jika budaya organisasi meningkat $1 \%$ maka kinerja karyawan akan meningkat 0,230.

Pengaruh Komitmen organisasi terhadap Kinerja Karyawan

Hasil penelitian ini membuktikan bahwa komitmen organisasi mempunyai pengaruh terhadap kinerja karyawan CV. AUTO 99 Malang. Dari hasil penelitian, pengujian statistik menunjukkan bahwa pengaruh langsung komitmen organisasi terhadap kinerja karyawan memiliki koefisien jalur sebesar 0,585 dan secara statistik signifikan pada level $\alpha=0,05$ yang ditunjukkan dengan nilai signifikan tabel sebesar 0,000 (lebih kecil dari 0,05).

Dari temuan statistik tersebut dapat dinyatakan bahwa komitmen organisasi kerja berpengaruh langsung dan signifikan terhadap kinerja (Y) sebesar 0,585 atau 58,5\%. Koefisien jalur sebesar 0,585 menunjukkan bahwa jika budaya organisasi meningkat $1 \%$ maka kinerja karyawan akan meningkat 0,585. Hasil ini menunjukkan bahwa komitmen organisasi kerja mampu memediasi variabel budaya organisasi terhadap kinerja karyawan.

Kesimpulan

Kesimpulan merupakan sebuah pernyataan singkat tentang hasil analisis deskripif dan pembahasan tentang hasil pengetesan hipotesis yang telah dilakukan di bab sebelumnya yang telah dipaparkan. Hasil nya adalah sebagai berikut:

1. Budaya organisasi berpengaruh secara langsung terhadap komitmen organisasi pada CV. AUTO 99 Malang.

2. Budaya organisasi berpengaruh langsung terhadap kinerja karyawan pada CV. AUTO 99 Malang.

3. Komitmen organisasi berpengaruh langsung terhadap kinerja karyawan pada CV. AUTO 99 Malang.

4. Budaya organisasi berpengaruh secara tidak langsung terhadap kinerja karyawan melalui komitmen organisasi pada CV. AUTO 99 Malang.

\section{Saran}

Bagi peneliti selanjutnya yang berminat untuk melanjutkan penelitian ini diharapkan untuk menyempurnakannya yaitu dengan menggunakan variabel lain yang berpengaruh terhadap kinerja karyawan, yang meliputi: kompensasi, komunikasi, pendidikan, pelatihan dan variabel lain yang berpengaruh terhadap dan kinerja karyawan sehingga penelitian tersebut dapat lebih berkembang dan memperluas wawasan.

\section{DAFTAR PUSTAKA}

1. Anwar Prabu Mangkunegara. 2009. Manajemen Sumber Daya Manusia Perusahaan. Bandung : PT. Remaja Rosda Karya.

2. Arikunto, S., 2006. Prosedur Penelitian Suatu Pendekatan Praktik. Jakarta: Rineka Cipta.

3. Fey, C.F.,\& Denision, D.R. (2003). Organizational Culture and Effevtiveness: Can American Theory Be Applied in Rusia? Organizational Science, 14 (6),686706.

4. Mathis, Robert L dan Jackson, John H 2004. Manajemen Sumber Daya Manusia, Buku ke dua. Salemba Empat Jakarta.

5. Robbins dan Judge. 2008. Perilaku Organisasi, Edisi Duabelas, Penerbit Salemba Empat: Jakarta.

6. Singarimbun, Masri dan Sofian Effendi, 2006, Metode Penelitian Survei (Editor), LP3ES, Jakarta.

7. Sugiyono, (2008). Metode Penelitian Kunatitatif Kualitatif dan R\&D. Bandung Alfabeta.

8. Sopiah. 2008. Perilaku Organisasi, Yogyakarta : Andi. 